\title{
A corpus-based study of metadiscourse markers in English and Urdu
}

Haroon Shafique

University of Lahore, Gujrat Pakistan

https://doi.org/10.36505/ExLing-2018/09/0024/000357

\begin{abstract}
Interactional metadiscourse markers are the self-reflective linguistic expressions that make the writers more powerful in interaction (Hyland, 2004). In this study, a large corpus has been compiled from English and Urdu newspapers. The compiled corpus is analyzed quantitatively as well as qualitatively to draw the results by using Hyland's (2005) model of interaction. The quantitative results exhibit that the news writers of English and well as Urdu prefer to manipulate the viewpoint of their readers by their judgments when they use stance markers. The contrastive analysis of interaction markers in both corpora reveals that Urdu journalistic discourse is more persuasive, convincing and influential as it consists more interaction markers as compared to English journalistic discourse.

Keywords: Metadiscourse, interactional markers, corpus
\end{abstract}

\section{Introduction}

Interactional metadiscourse has already been highlighted by so many linguists in the past and highlighted interactional metadiscourse in different genres as well as in different languages but there is hardly any research found on interactional metadisocurse in Urdu. Moreover, no contrastive study has yet been done to analyze interactional markers in English and Urdu in journalistic discourse.

The term metadiscourse is widely used in current discourse analysis and language education, referring to an interesting and relatively new approach to conceptualize interactions between text producers and their texts and between producers and users (Hyland, 2010).

Metadiscourse is specifically defined as "the linguistic resources used to organize the author's stance towards either its content or to the reader" (Hyland, 2000; p.109). On the other hand, metadiscourse is more generally seen as writer's linguistic and rhetoric manifestation in a text so as to bracket the discourse organization and the expressive implications of what is being said (Schiffrin 1980).

ExLing 2018: Proceedings of 9th Tutorial and Research Workshop on Experimental Linguistics, 28-30 August, Paris, Frannce 


\section{Research questions}

1. How differently interaction markers are used in English and Urdu journalistic discourse?

2. What kind of interaction markers are preferred in English and Urdu journalistic discourse; stance markers or engagement markers?

\section{Methodology}

This is a corpus-based study where mixed method approach is applied to find the results. The data is first quantified and then analyzed qualitatively. Hyland's (2005) model of interaction is applied to English and Urdu corpus to find out interaction markers in journalistic discourse.

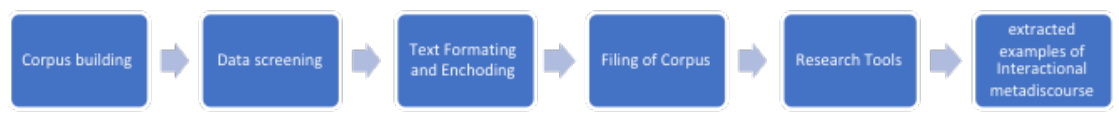

Figure 4 . The process of corpus building and analysis

\section{Theoretical framework}

The theoretical framework applied in this research is Hyland's (2005) model of interaction which analyzes the interactional features of discourse. Stance is called the textual voice which refers to the ways in which a writer projects himself in a text and conveys his judgments, opinions and commitments. On the other hand, engagement is the reader-oriented approach in which a writer recognizes the presence of others, pulls them along with his arguments (Hyland, 2005).

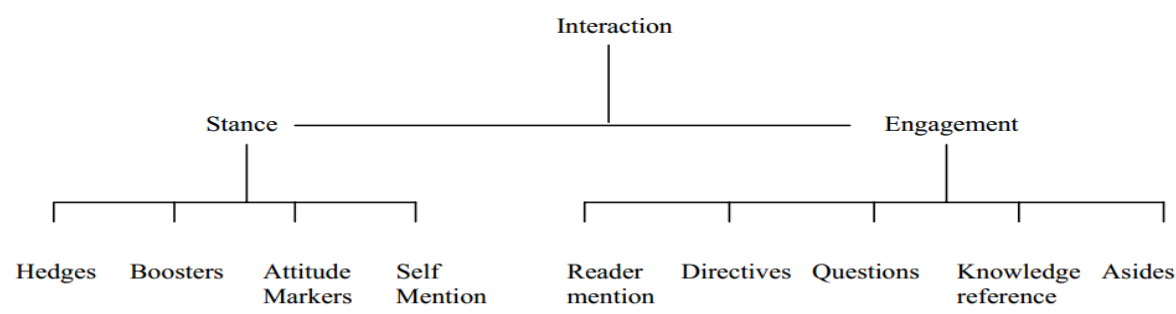

Figure 5. Hyland's model of Interaction (2005). 
Data analysis

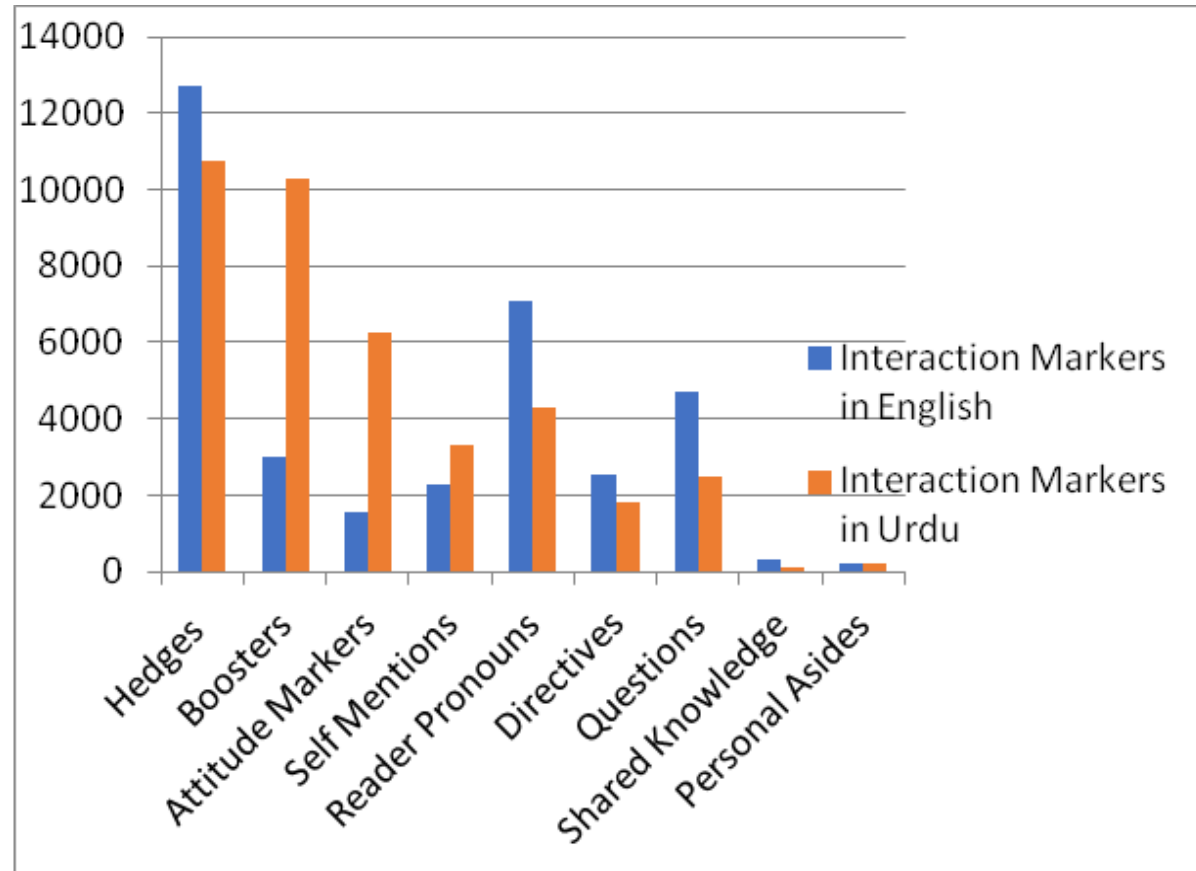

Figure 6. Interaction markers in English and Urdu

The graph above given exhibits the contrastive analysis of interaction markers i.e. stance markers and engagement markers in English and Urdu journalistic discourse. The graph shows, hedges are the only stance markers with high frequency in English discourse as compared to Urdu. The other three stance markers have high frequency in Urdu journalistic discourse than English. It implies that the English Journalistic writers prefer to use hedges more to project their stance while the rest of three stance devices are given less priority in English newspaper writing. As far as engagement markers are concerned, all the engagement markers have higher frequency in English newspaper writing than Urdu. It suggests that the journalistic writers of English prefer to use more engagement markers as compared to Urdu journalistic writers.

\section{Conclusion}

The findings of the study reveal many important facts. The quantitative analysis of the study shows that hedges are the most occurring Interaction markers in English and Urdu corpus which depicts that the 
uncertain statements are the core feature of Journalistic Discourse. The results exhibit that stance is the dominating category of metadiscourse markers in both journalistic discourses. The quantification of the corpus also highlights that the news writers of the Urdu language use more interaction markers as compared to the English news writers which implies that Urdu journalistic text is more persuasive, influential and convincing for the readers.

\section{References}

Hyland, K. 2000. Disciplinary discourse: Social interactions in academic writing. London: Longman.

Hyland, K. 2004. A convincing argument: Corpus analysis and academic persuasion. In Connor, U., Upton, T.A. (Eds.), Discourse in the professions: Perspectives from corpus linguistics 87-112. Amsterdam: John Benjamins.

Hyland, K 2005. Metadiscourse: Mapping Interactions in Academic Writing. University of London, UK

Schiffrin, D. 1980. Meta-talk: Organizational and evaluative brackets in discourse. Sociological Inquiry 50(3-4), 199-236. 